\title{
How to move forward and implement e-skills on a long term basis
}

\author{
E-skills are a strategic tool to develop innovation and meet \\ challenges deriving from globalisation
}

\author{
Franco Patini \\ Confindustria, Confederation of Italian Industry
}

Nowadays, e-skills concern an ample group of interested parties, in fact, considering the "digital citizenship" we might conclude that we are all involved, from those who use basic levels of "digital access" to ICT specialists.

Many are therefore the stakeholders operating on issues related to e-skills development: schools, Universities, public administrations, enterprises, political makers, associations, local governors, just to mention some of them.

Amongst all initiatives that Italy is carrying out, we deem important to highlight some of them having a particular value: those carried out within "the system".

We believe essential, at a Country level, without willing to obstacle single initiatives, private or public, or which are the result of Public - Private Partnership, to disseminate a common and shared model to define, describe and evaluate e-skills, able to cover the whole scenario, from e-citizens to informatics experts.

In the light of the foregoing, we can confirm that our Country has made an accurate choice testified by various initiatives now ongoing, as hereinafter briefly pointed out:

- The Italian Ministry of Employment, in organizing the Labour Bourse as a meeting place to exchange professionals demand and offer, has adopted the EUCIP model as the framework according to which professional profiles are described

- the National Committee of Informatics in Public Administration (CNIPA) is about to publish a recommendation to be applied by Public administrations in order to adopt the EUCIP framework as reference scheme for the evaluation of professional skills to be used in ICT public tenders

- In the academic ambit, Universities of Information Science and Informatics Engineering are introducing the EUCIP model (and relevant recognizing mechanism of curricula credits) to try to align academic skills, typical of university courses, to main skills required by the market. 
Together with those «institutional initiatives » many best practices can be mentioned: certain public administration offices, particularly attentive, as well as enterprises and professional institutions (for example the Association and Register of Engineers) are developing strategies that not only tend to evaluate and develop ICT skills (i.e. e-skills) but are build recurring always more often to the shared model.

In conclusions is always more diffuse the assumption that - in order to create a favourable environment for e-skills development, on long term basis - is essential, at a national level, but this of course applies to other Countries at EU level, the existence of an "e-skills framework" that has to be:

- $\quad$ shared

- not "owned"

- maintained and able to grow

- $\quad$ entrusted to an authoritative and not competitive entity

all, hopefully on an European scale. 